\title{
RAIMUNDA TORRES Y QUIROGA: UNA DESCONOCIDA AUTORA DE LITERATURA FANTÁSTICA EN LA ARGENTINA DEL SIGLO XIX
}

\author{
Carlos Abraham \\ Universidad de La Plata \\ carlosx106@yahoo.com.ar
}

Recibido: 14-03-2014

Aceptado: 22-04-2014

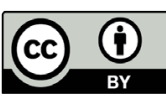

\section{RESUMEN}

Este ensayo está dedicado a analizar la producción fantástica y de terror de Raimunda Torres y Quiroga, escritora argentina que, utilizando diversos seudónimos, publicó sus textos en periódicos y revistas literarias del siglo XIX, compilándolos posteriormente en formato de libro. Sus textos fantásticos se caracterizan por su defensa de la mujer frente a la violencia masculina, presentando con frecuencia venganzas de ultratumba. Hasta el presente ensayo, era una autora ignorada por la crítica literaria.

Palabras Clave: Literatura fantástica, Raimunda Torres y Quiroga, terror, siglo XIX.

\section{ABSTRACT}

This paper focuses on the fantastic and horror tales by Raimunda Torres y Quiroga. She was an Argentine writer who, under several pseudonyms, published her work in nineteenth century newspapers and literary magazines. Her tales of the fantastic are a defence of women's rights against male violence. These tales often depict after death acts of revenge. Until now, she was completely absent in literary criticism unknown by literary critics.

KEYWORDS: Fantastic Literature, Raimunda Torres y Quiroga, horror, nineteenth century.

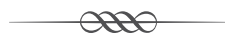


Uno de los episodios más enigmáticos de la literatura argentina se desarrolló entre 1878 y 1884. En el primero de esos años, una escritora que firmaba como Matilde Elena Wuili comenzó a publicar cuentos fantásticos y de horror en el diario La Nación y los semanarios femeninos La Ondina del Plata, La Lira Argentina, El Álbum del Hogar y La Alborada Literaria del Plata. Estos cuentos, que exhibían huellas de Hoffmann, de Poe y del Shakespeare más sangriento, llevaban como título general «Historias inverosímiles».

El interés del público se hizo sentir mediante cartas y hasta consultas en la sede de los periódicos. Para aplacar los ánimos, Josefina Pelliza de Sagasta, una de las principales colaboradoras de El Álbum del Hogar, publicó el 18 de abril de 1880 una nota en dicho semanario anunciando que Matilde Elena Wuili era un seudónimo y que la semana siguiente revelaría el verdadero nombre de la escritora. Lamentablemente, el 25 de abril la expectativa se ve frustrada:

En vista del deseo manifestado por nuestra bella amiga Matilde Elena, desistimos por el momento de descubrir un nombre que es ya una gloria nacional y que cubierto hasta hoy con un pseudónimo pasa ante los ojos del lector sin el doble interés que siempre inspira un nombre conocido. Conocemos y tratamos a la inteligente novelista, tan maestra en el manejo de la fantasía, pues todas sus obras dadas a luz en los periódicos son del género, tan bello como fantástico, de esas novelas increíbles que nos narran Hosfan [sic] y Poé [sic]. Ella cultiva con éxito feliz este extraño género, para cuya trabazón se necesita estar dotada de un vigor extraordinario en las concepciones, altamente fantásticas, y de un colorido que no es fácil disolver en la paleta donde se busca y halla tanto para el bosquejo de una novela de costumbres -donde todo es sencillo y natural.

Sus producciones forman parte de la colección que publicará en breve bajo el rubro de «Cuentos inverosímiles o Historias extraordinarias». No lo recuerdo bien. Cualquiera de los títulos es bonito, pero me gustaría más éste: «El cofre de joyas». ¿No es verdad, lectores?

El punto más destacable es, junto con la especificación de algunas de las lecturas de Wuili, que ésta no era una simple incursora en el fantástico, sino que tenía el proyecto (cumplido posteriormente) de realizar una serie sostenida de relatos pertenecientes al género. El artículo, única referencia biográfica sobre la escritora, también informa que tiene alrededor de veinte años, que aún no ha publicado libros y que ha utilizado diversos seudónimos, sin especificar cuáles.

Los seudónimos eran frecuentes en nuestra temprana literatura feme- 
nina. Algunas escritoras usaban nombres masculinos en la creencia de que uno de mujer no sería tomado en serio. Es el caso de Emma de la Barra, que utilizó «César Duayén». Otras firmaban con seudónimos femeninos, ya fuera para ocultar su verdadera identidad ante la opinión social o para no sobrecargar una revista determinada con excesivos trabajos bajo su nombre auténtico.

Los oscuros gustos de la autora (que pronto cambió la grafía Wuili por Wili) llamaron la atención de sus contemporáneos. Por ejemplo, en La Alborada del Plata (2 de mayo de 1880) apareció, en la anónima sección de gacetilla, el siguiente diálogo:

-No me gusta que me compares con Mandinga. Le tengo horror á ese caballero.

-No le sucede lo mismo á Matilde Elena Wili, que según me han contado, está zurciendo una colección de historias inverosímiles, donde figuran ejércitos de demonios, almas en pena, calaveras parlantes, espectros que hacen cabriolas sobre cráneos vacios, y otras cosas lúgubres.

Poco después apareció el anunciado libro, con un título bastante neutro: Entretenimientos literarios (Wili, 1884). Contenía la mayor parte de las contribuciones periodísticas de la autora. Estaba dividido en cuatro secciones: «Fantasías», compuesta por relatos fantásticos; «Retratos de brocha gorda», con piezas costumbristas y satíricas; «Misceláneas», cajón de sastre que incluye artículos sobre literatura, relatos amatorios y recuerdos de viaje; y «Páginas celestes», integrada por poemas en prosa.

El volumen me ha permitido descubrir la verdadera identidad de Wili. Incluye dos textos, «Las nupcias de la muerte» e «Historia de una calavera», que habían sido publicados en El Álbum del Hogar por Raimunda Torres y Quiroga, una escritora de aparición frecuente en las revistas literarias del período, pero de la que no se conocen datos biográficos.

También confirma la aseveración de Josefina Pelliza de Sagasta acerca de que usaba varios seudónimos, pues incluye textos que habían aparecido bajo los nombres «Celeste»y «Luciérnaga». En esto constituye un caso único en la literatura argentina. Otras autoras usaban un único seudónimo (como Mercedes Rosas, que empleó «M. Sasor») o a lo sumo variaban su firma según los avatares vitales (como Eduarda Mansilla de García, que en sus tímidos inicios se escondía tras el nombre «Daniel», al afirmarse su confianza artística utilizó su nombre completo y tras su ruptura matrimonial recurrió al autónomo «Eduarda»). Torres y Quiroga, a la manera de los heterónimos de Fernando Pessoa, emplea simultáneamente varios nombres, cada uno de los cuales 
remite a un posicionamiento estético determinado, a una «imagen de artista» específica. Así, Matilde Elena Wuili / Wili, con su aire centroeuropeo, es usado para textos fantásticos de cuño hoffmanniano. ${ }^{1}$ El chispeante «Luciérnaga» rubrica los textos satíricos y costumbristas. «Celeste», límpido y espiritual, se reserva para las prosas poéticas.

\section{LOS RELATOS FANTÁSTICOS}

La sección de Entretenimientos literarios titulada «Fantasías» está compuesta por diecinueve relatos. Poseen la particularidad de estar orientados casi en su totalidad al objetivo de producir un efecto de horror. Son clasificables en siete grupos: 1) Venganza sobrenatural; 2) Contacto fatal con lo sobrenatural; 3) Contacto inocuo con lo sobrenatural; 4) Textos moralistas; 5) Escenas de cementerio; 6) Textos macabros sin elementos sobrenaturales; y 7) Parodias macabras de textos infantiles.

El primer grupo está formado por relatos donde un hombre maltrata y finalmente mata a una mujer inocente, sufriendo como castigo una venganza sobrenatural. Lo componen «Gregorina», «Otto de Witworth», «La mancha de sangre», «La voz acusadora», «Eroteida»y «El secreto».

«Gregorina» está narrado en primera persona por un hombre que planea el asesinato de su mujer, debido a una voz inmaterial que le advierte sobre su infidelidad. La envenena poco a poco, colocando pequeñas dosis de veneno en su comida para disfrutar con su gradual debilitamiento. Cuando fallece, la voz susurra al protagonista «Ella era inocente».

«Otto de Witworth» transcurre en un castillo medieval durante una noche de tormenta. Un grupo de amigos brinda entre blasfemias. Estallan peleas y relumbran los cuchillos, algo habitual en la cofradía. Un espectro descarnado aparece gritando que Otto, el anfitrión de la fiesta, ha asesinado una muchacha. Se desvanece sin dejar rastros. Poco después llaman a la puerta: es un hombre idéntico a Otto, que saluda con cortesía y también se evapora en el aire. El acusado comprende que son manifestaciones de su conciencia manchada por el crimen y decide expiar sus culpas convirtiéndose en ermitaño.

1 Las wilis o willis eran criaturas sobrenaturales semejantes a vampiros femeninos, originadas a partir de los espectros de las doncellas muertas antes de su noche de bodas. Fueron popularizadas por el poema «De l'Allemagne» (1835) de Heinrich Heine, quien se documentó en leyendas folklóricas centroeuropeas. Según Heine, las wilis no descansan en sus tumbas ya que no pueden resistir el impulso de danzar desnudas y de atacar a hombres jóvenes en caminos desolados, obligándolos a danzar hasta que mueren de fatiga, en una especie de venganza contra el género masculino. El poema de Heine sería la inspiración del célebre ballet Giselle (1841). 
En «La mancha de sangre», un hombre decapita a su mujer por creerla (equivocadamente) culpable de traición. La cabeza seccionada rueda hasta él y grita que se vengará acosándolo en cada instante de su vida. Desde ese momento es acechado por una gran mancha roja, que se aparece en los lugares más insólitos para recordarle su crimen. El terror lo priva del sueño. Con el tiempo enloquece y queda ciego, pero aun así continúa viendo la aparición con sus ojos opacos. Años después se halla su calavera en un descampado, con una mancha roja en forma de cruz sobre la frente.

«La voz acusadora», influido por Poe, narra la repentina decisión de un hombre respecto a matar a su esposa. No tiene motivos para hacerlo, pues ella es bondadosa; la única razón que alega es que el genio de la perversidad se constituyó en su compañero. Esconde el cadáver y huye. Su corazón late más y más fuerte, hasta el punto de ensordecer sus oídos. Desesperado por el incesante golpeteo, confiesa su crimen.

«Eroteida» es la historia de un hombre enamorado de una bella pero misteriosa mujer. Una noche la encuentra leyendo un libro de magia escrito con caracteres cabalísticos. Su rostro está inclinado sobre el volumen; al levantarse, resulta ser el de un horrible espectro. El hombre se desmaya; cuando despierta, la apariencia de la mujer ha vuelto a ser la usual. Aterrado por haber descubierto lo que considera su verdadera naturaleza, la estrangula. El crimen no le trae tranquilidad, pues todas las noches lo acosa el espectro de la joven, con la mirada vidriosa y las violáceas marcas de sus dedos en la garganta.

En «El secreto», un grupo de amigos está reunido en una taberna. Uno de ellos anuncia que se aproxima la medianoche, la hora en que aparecen los espectros más horribles, y que deben tomar precauciones, ya que los seres del más allá lo acosan desde el momento en que mató a su esposa. Se levanta de su silla para dar cuchilladas al aire y cae al suelo sin vida, muerto de horror.

Estos seis cuentos son variaciones casi obsesivas de un tema que evidentemente fascinaba a la autora. «Gregorina», «Eroteida»y «La voz acusadora» están narrados en primera persona para presentar de modo más efectivo el avance de la locura en el protagonista. «El secreto» y «La mancha de sangre» en tercera persona, a fin de presentar del modo más explícito posible el castigo sufrido por los protagonistas masculinos.

El hecho de que siempre el victimario sea hombre y la víctima una mujer acusada de forma injusta y que suele ser su esposa (en «La voz acusadora» se agrega el detalle de que la mujer era golpeada con frecuencia), refleja que la intención de Torres y Quiroga no sólo es presentar un cuadro terrorífico 
sino también denunciar la violencia doméstica, que durante el siglo xIx fue apareciendo progresivamente en la literatura. ${ }^{2}$ Los agentes sobrenaturales que persiguen a los hombres violentos pueden ser vistos como una fantasía femenina de venganza, que busca en el más allá la justicia que la sociedad humana no proporciona. Lo cual es un posicionamiento explícito sobre la falta de leyes contra lo que hoy llamaríamos violencia de género.

El segundo grupo presenta una variación del argumento del castigo sobrenatural. No figuran mujeres en el rol de víctimas sino que la transgresión se produce por una ofensa a alguna entidad del más allá o por un crimen no conyugal. Esta hybris se castiga con la muerte repentina o con la locura. Lo componen «El baile de los muertos», «El heraldo de la muerte», «La sombra misteriosa», «Fritz Walker», «El hombre de la máscara roja»y «La plegaria de los muertos».

«El baile de los muertos» está ambientado en la Europa medieval, según revelan las referencias a la peste negra. Unos amigos brindan en una mansión durante una noche de tormenta, lo que constituye una de las ambientaciones favoritas de la autora. Espoleados por el alcohol, visitan el cementerio para reírse de los cadáveres empapados por el temporal. Entre carcajadas, excavan las sepulturas. Cuando llega la medianoche aparece una nube de espectros, que obliga a los profanadores a bailar una danza de aquelarre antes de su ejecución.

«El heraldo de la muerte» vuelve al tema del banquete celebrado en un castillo bajo una noche de tormenta. Un conde ahíto de crímenes festeja junto a sus amigos, cuando oyen un trovador que canta unas coplas de mal agüero, pronosticando la ruina de los contertulios. Furioso, el noble ordena que lo traigan para matarlo. Cuando aparece, quedan aterrados: se trata de un espectro. Al amanecer, del orgulloso castillo sólo perduran unos despedazados cimientos.

«La sombra misteriosa», de nuevo, presenta a un grupo de amigos en una taberna. El protagonista es contratado para un crimen. Cuando, tras matar a su víctima, se retira, escucha a una sombra susurrar que ha presenciado su crimen. Entonces, la ataca con su puñal, pero el golpe hiende el aire. La sombra seguirá al asesino día tras día hasta hundirlo en la locura.

Similar es «Fritz Walker», si bien no se explicita la causa del acoso. Dialogan un creyente en la existencia de seres sobrenaturales y un incrédulo. El

2 Especialmente en la novela gótica. Dos ejemplos son El matrimonio infeliz, donde aparece la violencia del marido contra la mujer, y La satisfacción generosa, que muestra la violencia del padre contra su hija (Céspedes y Monroy, 1800). 
creyente cita en su apoyo el caso de Fritz Walker, un individuo obsesionado por la idea de que un fantasma, con la forma de un hombre enmascarado e invisible para las demás personas, lo perseguía sin descanso. Vivía encerrado en su habitación y sólo se levantaba de noche. Durante mucho tiempo los médicos y los amigos trataron de hacerle olvidar esa monomanía, distrayéndolo, sacándolo a caminar en un día de sol o llevándolo de viaje. Todo fue inútil: aterrado ante el inmotivado acoso del espectro, Walker se fue consumiendo hasta morir.

«La plegaria de los muertos» transcurre en una noche de tormenta en la que un hombre recibe la visita de un amigo, pálido y cubierto de lodo. Con locura en la mirada, afirma que viene del cementerio y que ha oído la música de los muertos, tan maravillosa como el canto de las sirenas. Toma un violín e interpreta una lúgubre pero hermosa melodía. Cuando concluye, entra una muchedumbre de cadáveres, que aferra al artista y lo lleva al exterior, mientras el dueño de casa se desmaya. Al día siguiente, encuentra sobre la mesa una partitura titulada «La plegaria de los muertos». Nunca vuelve a ver a su amigo.

En «El hombre de la máscara roja» un estudiante es acosado por un hombre enmascarado que aparece tanto en la calle como en la universidad, en reuniones sociales o incluso en la soledad de su habitación, con mirada enrojecida y risa ultraterrena. La persecución se produce sin que el joven conozca el motivo. Sólo sabe de su perseguidor que se llama Robert Fitzmoor y que es respetado por los demás ciudadanos, que inexplicablemente parecen no advertir que siempre lleva su repulsiva máscara. Un día se despierta atado en un lecho mientras es contemplado por el enmascarado. Furioso, logra liberarse y lo mata a puñaladas. Entra una enfermera y grita que el paciente ha matado al médico del manicomio. El joven se desvanece al comprender que todo había sido un delirio. Cinco años después, se recupera y es dado de alta.

El tercer grupo está formado por los relatos que presentan un contacto casual pero no fatídico con lo sobrenatural. Lo forman «La cruz de brillantes» $\mathrm{y}$ «El viejo del gabán verde».

«La cruz de brillantes» combina elementos del policial y del fantástico. Un pensionista de un hotel londinense cae en un ensueño tras fumar una pipa de opio: recorre el espacio y el tiempo, visitando ciudades remotas y hombres antiguos. Al despertar, la ciudad está desierta, el hotel está vacío, la luz no enciende y sólo se oye un gemido que parece provenir de las entrañas de la tierra. Encuentra una cruz de brillantes; la guarda en su bolsillo sin intención de robarla. Luego se topa con un anciano cuyos pies no tocan el suelo. Relata 
haber presenciado el asesinato de una adúltera a manos del marido, enterado de la traición gracias a una cruz de brillantes obsequiada por el amante. Tras convocar al espectro de la mujer, que a regañadientes ratifica lo narrado, exige la devolución de la cruz. El protagonista intenta entregarla, pero ha desaparecido de su bolsillo. El anciano se desvanece en la oscuridad. Al día siguiente, el mundo ha vuelto a la normalidad. Hay gente en las calles y en el hotel, las luces funcionan y no se oyen ruidos subterráneos. Pero algunas cosas son desconcertantes, ya que se revela que gran parte de lo ocurrido en la noche fue imaginario. El protagonista descubre que la noche anterior estuvo jugando al ajedrez con el embajador austríaco y que el hotel estaba lleno de gente. Por último, lee en el diario que ha sido apresado un alquimista que a la misma hora en que ocurrió la visión mató a su mujer por creerla adúltera y le robó una cruz de brillantes. Como en «El hombre de la máscara roja», la autora consigue generar un efecto de disolución de la realidad que resulta casi dickiano. Ninguna de las certezas del protagonista resulta real. Incluso cuando las incógnitas parecen haberse despejado, perdura la duda de si se trata de nuevo de apariencias. La diferencia es que en «El hombre de la máscara roja» el motivo de la percepción distorsionada de la realidad era la locura; en este caso, se trata de las alucinaciones causadas por la droga.

«El viejo del gabán verde» combina la alucinación onírica con el tópico del encuentro con el espectro. El protagonista asiste a la ópera y a poca distancia se sienta un anciano de apariencia siniestra. Lo ve sacar unos anteojos de su bolsillo, limpiarlos con un pañuelo y ponérselos sobre la nariz; nada inusual, si no fuera porque estaban manchados con sangre fresca. A su lado hay una mujer alta y pálida, vestida completamente de negro. Inquieto, pregunta a otro espectador quién es esa mujer. La poco tranquilizadora respuesta es que se trata de una vampira. Se desmaya; al despertar, el teatro está vacío y un empleado le dice que no ha habido ninguna función operística. No es explicitado el motivo de la alucinación del protagonista, ya que en ningún momento se menciona su posible locura o el consumo de drogas. Las explicaciones posibles son una enajenación causada por la obra que está contemplando, o un episodio de sugestión hipnótica, a la manera de Mesmer, efectuado por el anciano.

El cuarto grupo está formado por textos con intencionalidad moralista y edificante, donde un ser sobrenatural apostrofa a los vivos. Lo integran «La mujer del collar de perlas», «El espectro»y «Un sueño».

«La mujer del collar de perlas» transcurre a la salida de una representación de Fausto. Un transeúnte se cruza con una mujer que sale del teatro, 
vestida de negro y adornada con un collar de perlas. Su siniestra belleza lo hace desvanecerse. Al despertar, se encuentra en una alcoba junto a la dama, que dice llamarse Realidad. Se besan: él declara su amor y ella se quita el collar de perlas. Instantáneamente se transforma en un esqueleto (el collar era símbolo de la belleza exterior). El hombre huye, pero una voz sepulcral dice a su oído que no debe asustarse de la realidad, pues la belleza es una simple ilusión que el soplo de la muerte desvanece.

En «El espectro», un joven se entretiene leyendo cuentos de fantasmas. Su profesión es indeterminada: en su cuarto tiene mapas, libros de ciencia y cajas de geometría, pero también elementos que permiten considerarlo como pintor (hay caballetes, telas y pinceles), como literato (hay manuscritos de poemas) y como músico (hay partituras y diversos instrumentos). Por lo tanto, es un símbolo de los anhelos intelectuales humanos. Escucha golpes a la puerta. Entra una figura envuelta en un sudario, que lo apostrofa diciendo que el ansia de figuración inmerecida, de ser célebre sin motivo, es la enfermedad del siglo xIx. El joven inquiere la identidad del intruso; éste responde que es el ser humano en su auténtica esencia. Se quita el sudario y revela ser un espectro.

«Un sueño» transcurre en una idílica mañana durante la cual la protagonista camina frente al Río de la Plata. En medio del éxtasis causado por la contemplación, se le acerca un ángel. Su nombre es Amor, y dice que su reinado ha llegado a su término, porque el materialismo se ha apoderado del mundo. Luego ve una vaporosa ondina, que dice llamarse Felicidad; también desaparecerá de la Tierra. Por último se le presenta la Amistad, quien afirma que en el siglo xIx los sentimientos nobles se han vuelto palabras huecas. En ese momento, la protagonista despierta sobresaltada: todo había sido un sueño.

Los tres textos coinciden en la crítica al materialismo, que impulsa a la valoración de lo externo y lo frívolo, desestimando valores más profundos. La diatriba contra el materialismo y el mercantilismo fue un tópico frecuente en la literatura de la Generación del Ochenta, período en el cual la modernización y el desarrollo económico experimentados por Argentina generó una traumática sensación de quiebre con respecto al pasado, percibido como más espiritual. Dentro de la literatura fantástica nacional, el tema aparece en «El ramito de romero» (1874) de Eduarda Mansilla de García, donde un joven incrédulo amplía su modo de pensar gracias a una visión.

El quinto grupo está formado por escenas de cementerio, un ámbito privilegiado del fantástico y del horror, al ser una zona de contacto entre el mundo de los vivos y el mundo ultraterreno. Lo forman «Las nupcias de la muerte» $\mathrm{y}$ «La tumba del vampiro». 
«Las nupcias de la muerte» ${ }^{3}$ presenta un hombre que vaga de noche por el cementerio, sin que se explique el motivo. Bajo la lápida de una doncella oye dos voces de ultratumba. Es un diálogo entre la joven y el gusano que ha de devorarla. La doncella -aún no consciente de su fallecimiento- abraza en el ataúd a su compañero, creyendo que es su esposo en la noche nupcial. El gusano la aterra, susurrándole que está en un ataúd, encerrada eternamente junto al ser viscoso que la devorará.

En «La tumba del vampiro», tras un epígrafe que cita un pasaje macabro de Macbeth, se narra un peregrinaje por una noche tempestuosa, donde los relámpagos se intercalan con el graznido de los cuervos. De pronto el protagonista se halla en el cementerio (lo cual incentiva el elemento mistérico al descolocarlo espacialmente). Ve en un nicho una calavera de la que emana luz y un sudario que se agita; al levantarlo encuentra cuatro mujeres jóvenes y bellas, aún no descompuestas. Luego el narrador se encuentra con un viejo sepulturero, que al enterarse de la calavera musita que se trata de la tumba de un vampiro.

El sexto grupo está formado por relatos macabros sin intervención de agentes sobrenaturales. Lo forman «Historia de una calavera», «Un crimen misterioso» $\mathrm{y}$ «Un episodio trágico».

En «Historia de una calavera», unos jóvenes visitan al doctor Rawlend. Todo en su casa es de color negro; el único objeto blanco es una calavera sobre una mesita. Los jóvenes dicen que el sitio es lúgubre, y Rawlend responde que más lo es la historia de la calavera. En sus tiempos de estudiante conoció una bella joven. Se enamoran a primera vista, pero el padre de la muchacha se niega a autorizar la boda. Rawlend la rapta y se casan; a la salida de la iglesia aparece el padre gritando que la boda no debe realizarse, porque son hermanos. Ella muere de un paro cardíaco y Rawlend cae desmayado. Al despertar, profana la tumba para conservar la calavera como reliquia.

«Un crimen misterioso» comienza con dos amigos paseando, cuando oyen gritos de auxilio. Encuentran una mujer desgreñada que intenta huir de unos matorrales. La detienen y encuentran el cuerpo de una niña que resulta ser su hija. La mujer es enjuiciada y torturada, pero no revela los motivos de su filicidio. Pocos días después, es ejecutada en una plaza pública. El texto, entroncado en la línea del folletín de hechos criminales (que hacía énfasis en

3 Una nota aclara que se trata de una imitación de la comedia La mort de Théophile Gautier. Se trata de La comédie de la mort (1838), en realidad un extenso poema con algunas escenas dialogadas. Un fragmento, titulado «La vida en la muerte», había sido publicado en el diario La Nación (Gautier, 1880); se trata precisamente de la sección que inspiró el texto de Torres y Quiroga. 
los asesinatos truculentos, en las mutilaciones y en las intrigas familiares), tiene como elemento extraño la negativa de la madre a revelar las causas de su crimen. Ello resulta interesante desde el punto narrativo, ya que conduce a la especulación acerca de cuáles habrán sido los motivos de la mujer. ¿Locura, una naturaleza criminal, o alguna causa oculta y siniestra? El despojamiento narrativo y la falta de explicación de los motivos del hecho sangriento generan un tono enigmático y poco convencional, que incrementa la incógnita. Otro elemento significativo es la ausencia de toda alusión al padre de la víctima. Ello puede indicar un intento de venganza por parte de la mujer hacia el hombre, al estilo de Medea. Otra posibilidad es que, por el contrario, el mutismo de la mujer se deba al encubrimiento de la participación del esposo en el crimen.

«Un episodio trágico» aprovecha el potencial macabro de las epidemias porteñas. En 1871 muere de fiebre amarilla una muchacha que había sido muy mimada por sus padres. Cuando la joven expira, la madre, también enferma, muere instantáneamente de tristeza. El marido, ante la doble fatalidad, se echa a gemir y a reír de forma convulsiva: se ha vuelto loco.

El séptimo grupo, cuyo tema es la parodia en tono macabro de los cuentos infantiles, está formado por un solo texto: «La muñeca parlante». Es un breve relato de horror con intencionalidad moral, tono de cuento de hadas y una niña como protagonista. Probablemente fue inspirado por la coetánea publicación de Cuentos (1880) de Eduarda Mansilla de García, primer libro argentino dirigido a un público infantil. De ser así, representaría una interesante apropiación de dicho género por parte de nuestra autora, ya que hábilmente inserta en el marco típico de los relatos infantiles (entorno familiar, estilo llano, punto de vista de un niño, final feliz) el toque macabro que la caracteriza, mediante la utilización de un personaje esencial en el fantástico decimonónico: el autómata. Dado que Cuentos fue una obra muy difundida en el período, puede conjeturarse que Torres y Quiroga haya querido jugar a realizar una versión de esos relatos infantiles con su personal registro macabro. La protagonista es Carlota, una niña de doce años «que no sabe leer, coser ni rezar». Es, pues, una niña mala. Todo cambia cuando le regalan una gran muñeca parlante. Ésta cobra vida cuando están solas y amenaza con llamar al diablo si la delata, y con matarla si no estudia y se porta bien. La niña, aterrada por esta inesperada institutriz, se vuelve buena; con el tiempo, termina casándose y teniendo dos hijos. Es decir, viviendo la vida que los tradicionales cuentos de hadas consideran el cierre exitoso de un destino femenino. 
AsPeCtos TEMÁTICOS Y FORMALES

La Generación del Ochenta no fue monolítica en cuanto a su posicionamiento filosófico y religioso. Si bien eran más visibles los sectores plenamente comprometidos con el positivismo, que desde el punto de vista ideológicoreligioso tendían a ser deístas, agnósticos o ateos, también abundaban los católicos practicantes como Santiago Estrada e Ignacio Vélez. Nuestra autora, a juzgar por el testimonio de sus ficciones y ensayos, estuvo enrolada en el segundo grupo. Cito su relato realista «La hija del salvaje»:

La humanidad no podría existir sin religión y tanto es así, que desde el principio del mundo no ha habido un pueblo de ateos. ¡La creencia en un ser superior que rige los Orbes ha prevalecido hasta en los salvajes! Sin religión el mundo moral se derrumbaría (Wili, 1878).

Esta religiosidad de Torres y Quiroga es determinante para que sus cuentos fantásticos tengan una fuerte carga moralista. «La mancha de sangre», «La voz acusadora», «Eroteida», «El secreto»y «La sombra misteriosa» relatan asesinatos inmotivados que no han sido castigados por la justicia; las continuadas apariciones del espectro de la víctima, al que también cabe interpretar como una corporización del remordimiento, llevan al criminal a la locura o a la confesión. En «Gregorina» ocurre un asesinato a causa de un supuesto adulterio; no hay acoso desde el más allá, pero el criminal se ve torturado por la revelación de que ella le había sido fiel. En «Otto de Witworth « $\mathrm{y}$ «El heraldo de la muerte», unos aristócratas tiránicos son interpelados por seres sobrenaturales. En «El baile de los muertos», unos profanadores de tumbas son asesinados por cadáveres redivivos. En «El espectro», un disoluto joven recibe la admonición de un fantasma, que le recomienda aplicarse a sus estudios y ser humilde.

En otras palabras, el fantástico de Torres y Quiroga suele ser un fantástico edificante, que contiene fuertes elementos de moral religiosa. Existe la noción constante de que cada acto humano es observado y castigado por una justicia que no es de este mundo. Se trata de una diferencia, por lo tanto, con respecto a Poe o Hoffmann, autores donde los sucesos sobrenaturales, prístinos e inexplicables, no admiten explicación de orden moral.

El crimen, en sus relatos, es una puerta al fantástico, ya que motiva la intervención sobrenatural. Otras puertas al fantástico, de menor importancia, son la alucinación causada por las drogas («La cruz de brillantes»), la obsesión 
enfermiza por el arte («La plegaria de los muertos») y la llana y simple locura («Fritz Walker», «El hombre de la máscara roja»). En estos últimos casos, el contenido moralista está ausente.

Un punto importante es que el castigo sobrenatural del crimen no es de naturaleza divina, ya que en ninguna de las ficciones se mencionan elementos del panteón cristiano. No aparecen, santos o la propia divinidad; de hecho, brillan por su ausencia. El orden proviene siempre de una innominada e indeterminada justicia ultraterrena (interpretable de un modo sobrenatural como el espectro de la víctima, o, de un modo racional, como el efecto de una conciencia culpable). Ello expresa implícitamente, como ocurre en «El ramito de romero» de Eduarda Mansilla de García (donde en una visita al más allá aparecen elementos tomados de la teosofía) y en la literatura de orientación espiritista (movimiento que buscaba convertirse en una alternativa al dogmatismo del catolicismo), la fatiga del paradigma católico en el imaginario social de la Generación del Ochenta. No hay duda de que Torres y Quiroga apoyaba sin reservas al dogma católico en su vida cotidiana, pero la axiología interna de su ficción tiene una lógica propia y autónoma, que trasciende sus convicciones personales. Esto es algo común en los textos fantásticos, que deben trabajar continuamente con la creación de un verosímil narrativo, a fin de ser convincentes. Para la creación de ese verosímil, deben emplear los recursos y temas que en el imaginario social de su tiempo son considerados como válidos. No hubiera sido efectivo que Torres y Quiroga mostrara un arcángel con una espada llameante castigando a sus hombres violentos; en cambio, utiliza los agentes misteriosos y esotéricos propios de la tradición secularizada del fantástico occidental decimonónico: el espectro, el muerto redivivo, el vampiro. Esa tensión entre el dogma religioso adoptado en la vida personal y los imperativos y requisitos de la narrativa generan la paradoja de que una autora católica no utilice los recursos de la religión a la que pertenece, sino otros que en la lógica interna de la serie literaria resultaban más convincentes.

Desde el punto de vista formal, sus relatos están construidos de forma cuidadosa. Carecen de digresiones, lo que evita que se debilite el impacto de lo narrado (esto, quizá, es consecuencia tanto de una buena conciencia narrativa como de las limitaciones de espacio existentes en los medios hemerográficos donde publicaba). Suelen comenzar describiendo un entorno cotidiano en el que la progresiva introducción de elementos inquietantes, así como el adecuado crescendo de la tensión, genera una sutil y no forzada presentación de lo fantástico. También son frecuentes los giros argumentales sorpresivos y 
las elipsis de escenas innecesarias, a fin de mantener el dinamismo de la trama. En este sentido, Torres y Quiroga toma los mejores rasgos del folletín decimonónico (el suspenso, el dramatismo y hasta una irónica truculencia) sin caer en sus defectos (excesivas digresiones, prolongamiento artificial de escenas).

Los protagonistas principales de sus relatos fantásticos pertenecen siempre al sexo masculino. En cambio, en los textos satíricos y en las prosas poéticas pertenecen siempre al sexo femenino. Ello se debe a dos razones: por un lado, la relativa ausencia de una tradición fuerte de fantástico escrito por mujeres (mientras que en la poesía y en las gacetillas satíricas había preponderancia femenina); y, por otro, debido a los requerimientos de la trama, ya que se trata generalmente de criminales sobre los que recae la fatalidad a causa de actos violentos contra mujeres. No se puede entender el fantástico de Torres y Quiroga sin tener en cuenta el tema de la violencia intergenérica.

\section{LAS LECTURAS DE LA AUTORA}

La determinación de las lecturas de Torres y Quiroga es una empresa estimulante, ya que demuestra haber conocido a la mayor parte de los creadores de literatura fantástica de su tiempo.

Ernst Theodor Amadeus Hoffmann aparece de modo explícito en «Eroteida», donde se lo cita en el epígrafe. Puede apreciarse su influencia en rasgos como la confusión entre sueño y realidad, la presencia de ancianos siniestros, el uso del grotesco, los autómatas y el interés por la locura. Por su parte, en «La cruz de brillantes» emplea la indeterminación entre el mundo onírico y el real (cuyo paradigma hoffmaniano es «La princesa Brambilla»), así como un típico personaje del autor alemán: el anciano siniestro dotado de poderes incomprensibles. Otro ejemplo de ambos rasgos es «El viejo del gabán verde», donde el protagonista se llama «Consejero K.», lo que remite al Consejero Krespel del cuento homónimo de Hoffmann.

Muchos relatos de la autora tienen ambientación germánica. El propio seudónimo Wuili / Wili tiene resonancias teutonas. Esta noción de que para escribir literatura fantástica había que disfrazarse de alemán -es decir, disfrazarse de Hoffmann-, era sumamente frecuente entre los creadores de literatura fantástica del siglo xIx.

Otro autor cuyas huellas son evidentes es Edgar Allan Poe, al que Torres y Quiroga menciona de modo explícito en «La muñeca parlante» y en «La sombra misteriosa». 
Los títulos de algunos relatos de la escritora argentina son derivativos de otros del poeta norteamericano: «El hombre de la máscara roja» remite al poesiano «The Mask of the Red Death»; $y$ «La voz acusadora» recuerda a «The Tell-Tale Heart», que puede traducirse como «El corazón delator» $\mathrm{O}$ «El corazón acusador».

También utilizó estrategias de Poe para enfatizar el efecto de horror en sus cuentos. Por ejemplo, la mención al encanecimiento repentino de los personajes luego de experimentado el hecho insólito. Así, en «A Descent into the Maelstrom» se lee: «Mi cabello, negro como ala de cuervo la víspera, estaba tan blanco como lo ve usted ahora. También se dice que la expresión de mi rostro ha cambiado» (Poe, 1990: 157). En «Historia de una calavera» aparece el mismo recurso: «Había envejecido prematuramente. Mis cabellos antes negros como el ala del cuervo, ostentaban en algunas partes hilos de plata» (Wili, 1884: 143). Otro procedimiento como es la repetición de frases en boca de los enajenados, a fin de poner de relieve su psicología obsesiva, es utilizado en «La voz acusadora» y «El hombre de la máscara roja». Lo mismo ocurre con el tópico del ojo perturbador, presente en «El corazón delator», donde el narrador afirma:

Me parece que fue su ojo. ¡Sí, eso fue! Tenía un ojo semejante al de un buitre. Cada vez que lo clavaba en mí se me helaba la sangre (Poe, 1990: 131).

Recurso que es transportado de esta forma a «La sombra misteriosa»:

Yo temblé involuntariamente al verle penetrar en la taberna. Su ojo de buitre hambriento se fijó en mí de una manera fascinadora (Wili, 1884: 154).

Otra estrategia poesiana es la explicación del carácter inmotivadamente maligno de algunos de sus personajes (que los lleva a cometer crímenes sin la existencia de un móvil) en base a lo que denomina el impulso de perversidad o de fatalidad. Es decir, una inclinación latente e irrefrenable hacia el mal, que acecha en forma larvada dentro de todo ser humano. Los textos donde aparece este concepto son «The Black Cat»y «The Imp of Perverse». En Torres y Quiroga es utilizado en numerosas ocasiones. Por ejemplo:

Desde el instante en que el genio de la Perversidad se constituyó en mi inseparable camarada, la actividad de mi alma se desarrolló de una manera funesta, terrible (Wili, 1884: 43). 
No sé si fue el demonio de la fatalidad o el genio del Crimen -tal vez los dosque deslizaron a mi oído estas palabras: ¡Espectro! ¡Magia! (Wili, 1884: 105).

El alcohol no es otra cosa, muchas veces, que un instrumento de que se vale el demonio de la fatalidad para revelar crímenes que han tenido por testigos a las sombras de la noche (Wili, 1884: 149).

En cuanto al aspecto temático y estructural, hay una estrecha similitud entre «The Black Cat», «The Tell-Tale Heart» y «The Imp of Perverse» de Poe $\mathrm{y}$ «La mancha de sangre», «La voz acusadora», «Eroteida», «El secreto» $\mathrm{y}$ «La sombra misteriosa» de nuestra autora. Se trata de monólogos narrativizados en primera persona, donde los protagonistas relatan asesinatos que cometieron de modo inmotivado, sin recibir el castigo de la justicia humana pero sí el de la justicia sobrenatural. El caso más extremo de similitud se produce entre «La voz acusadora» $\mathrm{y}$ «The Tell-Tale Heart»: en ambos los protagonistas son inducidos a la locura debido al latido del corazón de la víctima.

Por último, «El espectro» presenta a un hombre que lee en su habitación durante la medianoche y oye una llamada a la puerta; al abrir no encuentra a nadie, pero cuando se repite la llamada es visitado por un fantasma. Es decir, un planteo similar al poema «The Raven», con el cambio de la naturaleza del visitante. El relato abunda en transcripciones casi exactas del poema, incluidas quizá debido a la similitud de atmósfera. Bastará un solo ejemplo:

Mi bien amada, la incomparable virgen que los mortales llamaban Olga! (Wili, 1884: 67).

Mi perdida Leonora, la incomparable y radiante virgen que los ángeles llaman Leonora (Poe, 1879).

Ann Radcliffe fue uno de los principales exponentes de la novela gótica inglesa. Por dicha razón, se convirtió en un emblema de la narrativa gótica en el imaginario cultural argentino del siglo xIx (así como Verne lo fue con respecto a la ficción científica): cada vez que se buscaba describir una obra de naturaleza macabra, era costumbre aludir a la narradora inglesa.

Además de por su visibilidad en el mercado literario, es posible que Radcliffe haya atraído a Torres y Quiroga por ser mujer y por presentar heroínas victimizadas por hombres crueles. La diferencia es que en Radcliffe la víctima siempre sobrevive; en Torres y Quiroga, nunca. 
En «Historia de una calavera», Torres y Quiroga menciona a Ann Radcliffe al describir la casa de Rawlend, decorada íntegramente de color negro:

Anna Radcliffe, la escritora por excelencia de lo extraordinario, hubiera encontrado en los tapices fúnebres de aquel gabinete, tema para trazar el más bello de sus cuentos (Wili, 1884: 121).

Otro célebre autor de la época como Heinrich Daniel Zschokke es mencionado explícitamente en «El espectro»:

Al verme solo en mi gabinete de estudio, acerqué una butaca a la mesa y me puse a leer los cuentos del poeta alemán Zschokke.

Un pequeño ruido, que parecía partir de la pieza contigua, me hizo levantar la cabeza.

-¡Bah! -me dije. Sin duda es el viento que penetra por las rendijas de la puerta, y continué leyendo El muerto desposado (Wili, 1884: 66).

El texto había sido traducido como El muerto prometido; la leve diferencia de título me ha permitido hallar la fuente exacta de la que abrevó la autora. Se trata de una versión aparecida en el periódico literario español El Museo de las Familias (Zschokke, 1839). Su trama es muy cercana a los gustos de Torres y Quiroga: criminales castigados por una intervención sobrenatural.

Eduardo Ladislao Holmberg, el principal autor de literatura fantástica en la Argentina del siglo xIx, fue conocido por Torres y Quiroga, ya que ésta lo menciona explícitamente en varias de sus gacetillas. La influencia más clara es el relato «La pipa de Hoffmann» (Holmberg, 1876), donde la inhalación de una pipa de opio produce extrañas visiones, de modo similar a lo que ocurre en «La cruz de brillantes».

Un texto interesante para la elucidación de las lecturas de Torres y Quiroga es el artículo «Supersticiones y creencias», incluido en la sección miscelánea de Entretenimientos literarios. Se trata de un panorama del folklore maravilloso de Suiza y Escocia. Del primer país menciona los duendes de la montaña o Bergmannlein, considerados maléficos por los pastores, y diversas leyendas regionales: un lago embrujado que contiene el cadáver de Poncio Pilatos, un puente construido por el diablo para obtener el alma de un hombre, una flor que crece en las cumbres más inaccesibles durante un solo día del año y que proporciona la felicidad eterna a quien la encuentre. Del segundo destaca las brujas, organizadas en escuadras por el diablo, y cuyas ocupacio- 
nes durante los aquelarres incluyen abrir los sepulcros y hacer ungüentos mágicos con la carne de los niños sin bautizar.

El artículo es un resumen de varios tratados folklóricos y relatos de viajes que estaban en boga durante la época. En lo relativo al folklore suizo, su fuente es Alemania: apuntes a vuela pluma (Perchet, 1878). Con respecto al escocés, la fuente es Historia de los demonios y de las brujas de Walter Scott, que, si bien pretende dar un panorama continental de su tema, se basa casi exclusivamente en ejemplos escoceses. ${ }^{4}$

Es posible señalar otras influencias menores. En algunos casos, se trata de autores citados de modo directo; en otros, de influencias reconocibles a nivel argumental.

«La cruz de brillantes» menciona La vuelta al mundo en ochenta días de Julio Verne. El autor francés era popular en Argentina, pero no existen huellas de su obra en Torres y Quiroga. Probablemente el objetivo de la referencia fue contribuir a la atmósfera del relato a través de la mención de un autor afiliado a la ciencia ficción.

«La mujer del collar de perlas» remite al título del cuento «La mujer del collar de terciopelo» de Alejandro Dumas, incluido en el volumen Los mil y un fantasmas (Dumas, 1849).

El nombre del doctor Rawlend en «Historia de una calavera» puede estar inspirado en el doctor Ruthven del cuento «The Vampire» (1819) de John Polidori. Dos ediciones circulaban en español: El vampiro: novela atribuida a Lord Byron (Polidori, 1824) y El vampiro o La sangre de las víctimas (Polidori, 1843).

Por su parte, Shakespeare es frecuente en los epígrafes, sobre todo sus piezas con elementos fantásticos, como Macbeth (con su aquelarre de brujas) y Hamlet (con el espectro del rey). Tras comparar las citas con las muchas traducciones circulantes en el período, he podido determinar que la versión empleada por Torres y Quiroga es Dramas de Guillermo Shakespeare (Shakespeare, 1881).

En «El viejo del gabán verde», uno de los protagonistas se llama Redlaw, como el profesor de química de «The Haunted Man and the Ghost's Bargain» (1848) de Dickens. De ese cuento hubo muchas ediciones en español, recogidas en los siguientes volúmenes: El hombre y el espectro o El pacto. Cuento fantástico (Dickens, 1849), Cántico de noche buena (Dickens, 1883), El endemoniado (Dickens, s/f) y El cántico de navidad (Dickens, 1883).

4 La edición de Letters on demonology and witchcraft (1848) manejada por Torres y Quiroga fue la publicada pocos años antes por Juan Oliveres (Scott, 1876). 
En «La mancha de sangre» aparece una mancha roja en forma de cruz grabada en una calavera: algo similar a lo que ocurre en «El clavo» de Pedro Antonio de Alarcón, donde se descubre una calavera con un clavo incrustado que había sido invisible a la autopsia. Su primera edición figura en Cuentos, artículos y novelas. Cuarta serie (Alarcón, 1859).

«La plegaria de los muertos» muestra un violinista que pierde la razón en su busca de una melodía perfecta, situación que recuerda a «El canto de la sirena» de Miguel Cané, donde un violinista busca también una melodía perfecta y enloquece debido a la intensidad de su belleza (Cané, 1877).

En «La mujer del collar de perlas» hay un epígrafe tomado de «El rayo de luna», una de las narraciones más difundidas de Gustavo Adolfo Bécquer, y una de las que juega más abiertamente con la temática fantástica.

En «Historia de una calavera», la escena del protagonista conservando el cráneo de su novia puede estar inspirada en La quena de Juana Manuela Gorriti, donde Hernán conserva el esqueleto de Rosa, usando su tibia para construir una quena. Torres y Quiroga fue colaboradora de La Alborada del Plata, dirigida por Gorriti, por lo cual es posible que no haya desconocido ese precedente.

Buena parte de estas influencias son mencionadas en un delicioso pasaje de «La sombra misteriosa», donde un monólogo del enajenado protagonista reivindica numerosos autores del género fantástico:

Para vosotros, Hoffmann no es más que un narrador fantástico, Edgar Allan Poe un poeta de imaginación extraña, Enrique Zschokke un visionario, Anna Radcliffe una escritora de cuentos inverosímiles, Erckmann Chatrian un soñador. Y sin embargo, sus personajes, llámense Crespel, Hollands, Zumbas, Nideck, Edward, son tipos que existen en el mundo, como es posible el Redlaw de Charles Dickens. «Hay hechos en la vida real que esconden y sobrepujan a las invenciones más ridículas y extravagantes de los novelistas», ha dicho Soulié (Wili, 1884: 150).

\section{CONSIDERACIÓN FINAL}

Raimunda Torres y Quiroga es una desconocida para la crítica literaria, tanto bajo su propio nombre como bajo el d

e sus seudónimos. No es algo sorprendente: si la literatura argentina del siglo xIx ha sido poco explorada, la escrita por mujeres lo ha sido menos aún. A esta situación contribuyeron la reducida tirada de su único libro (una 
autoedición), su anodino título y el apellido Wuili / Wili, que puede haber hecho suponer que se trataba de una autora extranjera.

Fue la tercera mujer que cultivó el fantástico en Argentina, después de Juana Manuela Gorriti y de Eduarda Mansilla de García. Como sus precursoras, mostró tendencia hacia el tremendismo, los golpes de efecto y los trucos de folletín; también se emparenta con ellas por sus numerosas apariciones en periódicos y revistas literarias. Se diferenció por su dedicación casi exclusiva a la literatura fantástica, así como por su consistencia en el cultivo de dicho género (una veintena de cuentos en siete años).

Haciendo un balance, entre los puntos negativos cabe señalar que parte de su obra es de carácter epigonal, llegando en algún caso específico («La voz acusadora») a la reproducción mimética de su modelo. También, que su paso por las letras fue fugaz: tras la publicación de su único libro, su nombre no volvió a aparecer en periódicos o revistas literarias. Quizá el algo despectivo título Entretenimientos literarios sea una expresión de hastío con respecto a la escritura.

Entre los rasgos positivos, destacar el estilo y la estructura de sus relatos, que revelan una intensa preocupación estética, así como la capacidad de generar atmósferas lúgubres con gran economía de recursos. Asimismo, también merece subrayarse la habilidad con que realiza trastrocamientos de la realidad en «La cruz de brillantes», «El hombre de la máscara roja» y «El viejo del gabán verde», entremezclando eventos reales con oníricos. Por último, señalar que su obra, en su reducido ámbito de difusión, enarboló la bandera de la literatura fantástica en nuestro país, generando revuelo en el momento de su publicación hemerográfica por el hecho de consistir de textos macabros y de estar escrita por una mujer.

Espero que este ensayo reviva el interés por esta soñadora proveniente de un ayer olvidado.

\section{BIBLIOGRAFÍA}

Alarcón, Pedro Antonio de (1859): Cuentos, artículos y novelas. Cuarta serie, Imprenta de El Atalaya, Madrid.

CAné, Miguel (1877): «El canto de la sirena», en Ensayos, Imprenta de la Tribuna, Buenos Aires.

CÉSPEDES y MonRoy, Atanasio (1800): Lecturas útiles y entretenidas, Imprenta de Josef Doblado, Madrid.

DiCKens, Charles (1849): El hombre y el espectro o El pacto. Cuento fantástico, Imprenta de L. García, Madrid. 
(1883): Cántico de noche buena, Biblioteca Universal, Madrid.

(1883): El cántico de navidad, Biblioteca Universal, Madrid.

(s/f): El endemoniado, Librería de Pascual Aguilar, Madrid.

Dumas, Alejandro (1849): Los mil y un fantasmas, Imprenta y Librería de Mayol, Barcelona.

GAUTIER, Théophile (1880): «La vida en la muerte», La Nación (21 de octubre).

Holmberg, Eduardo Ladislao (1876): «La pipa de Hoffmann», El Plata Literario (15 de junio-15 de septiembre).

Perchet, Augusto (1878): Alemania: apuntes a vuela pluma, Librería de Bailly-Bailliere, Madrid.

PoE, Edgar Allan (1879): «El cuervo», La Ondina del Plata (2 de marzo). (1990): Cuentos, Alianza Editorial, Madrid.

POLIDORI, John (1824): El vampiro: novela atribuida a Lord Byron, Imprenta de Narciso Oliva, Barcelona.

(1843): El vampiro o La sangre de las víctimas, Oficina del Establecimiento Central, Madrid.

Scotт, Walter (1876): Historia de los demonios y de las brujas, Librería de Juan Oliveres, Barcelona.

Shakespeare, William (1881): Dramas de Guillermo Shakespeare, Verdaguer, Barcelona.

Wili, Matilde Elena (1878): «La hija del salvaje», La Ondina del Plata (8 de diciembre). (1884): Entretenimientos literarios, Imprenta Colón, Buenos Aires.

ZsснокKE, Heinrich Daniel (1839): «El muerto desposado», El Museo de las Familias, vol.

II, pp. $480-483$. 